\title{
THE IMPACT OF COMPOSITIONS FROM HYDROLYTIC RESIDUES ON CHERNOSEM SOLONETS FERTILITY
}

\author{
Andrei Siuris \\ Institute of Soil Science, Agrochemistry and Soil Protection "N. Dimo", \\ MD-2070, 100, Ialoveni str., Chisinau, Republic of Moldova, \\ email: ipaps_dimo@mtc.md,: Phone:(373)22-284435; fax(373)-22-284855
}

\begin{abstract}
The results of different experimental modalities of residues from biochemical plants which function on the basis of hydrolysis (hydrolytic lignin, hydrolytic slime) as black soil solonets fertilizer and amendment are presented in the given paper. From the ecological and economic points of view, a new technology of chemical amelioration of alkaline soils with excessive administration of components from hydrolytic residues as soil ameliorators is founded.
\end{abstract}

Keywords: wastes, hydrolytic lignin, hydrolytic slime, chemical amelioration, solonets.

\section{Introduction}

An enormous quantity of residues is accumulated as result of any human activity. Being neutralized because of different reasons (psychological, economic, legal, technological, etc.) they cause an ecologic imbalance in nature, disturbing in such a way the normal functioning of the soil, of the atmosphere and of the aquatic resources. At the same time, the residues contain considerable quantities of elements necessary for the nutrition of the plans and for soil fertilization. In the present conditions, when the application of industrial fertilizers decreased to minimal quantities, the extensive utilization of residues, especially of organic ones is of especially significant importance for agriculture.

The rational production and utilization of ameliorators from hydrolytic residues might solve two important issues: the first is an ecological one: the diminishing of environment pollution with nutrients, and the second - the improvement of soil fertility.

\section{Materials and methods}

The research has been carried out by experiments, in vegetation vessels and in the field. The soil under experimentation is characterized as chernozem solonets possessing a moderate content of sodium (18-23\%), exchangeable magnesium (33-38\%), sodium-sulfate salinity, and a clay texture.

For the experiments in vegetation vessels we used the ploughed layer (0-25) evacuated on a plot of the agricultural farm from the village Ciuciueni, Sangerei district. The vessel had a capacity of $28 \mathrm{dm}^{3}$ and a bottom with holes. The preparation of the soil included the crumbling of the boulders having dimensions larger than $10 \mathrm{~cm}$ and homogeneity of the whole soil mass necessary for the experiment. The soil and the cultivated corn were provided with water from the atmospheric precipitations.

We made experiments on the residues from the biochemical plants that produce fodder yeasts (hydrolytic lignin and hydrolytic slime) separately and in in various combinations of sludge from urban waste water treatment and defecation mud from sugar mills (Table 1).

Table 1

The indicators of residues used in experiments, $\%$ of dry mass

\begin{tabular}{|c|c|c|c|c|c|c|c|}
\hline Residue & Humidity & $\mathbf{C}$ & $\mathbf{N}$ & $\mathbf{P}_{2} \mathbf{O}_{5}$ & $\mathbf{K}_{2} \mathbf{O}$ & $\mathrm{CaO}$ & Ash \\
\hline \multicolumn{8}{|c|}{ Experiment in vegetal vessels } \\
\hline Hydrolytic lignin (HL)* & 58.7 & 37.4 & 0.46 & 0.14 & 0.11 & 1.0 & 18.0 \\
\hline Hydrolytic slime (HS) & 62.4 & 29.5 & 0.78 & 0.24 & 10.9 & 10.9 & 37.5 \\
\hline Defecation mud (DM) & 23.5 & 3.7 & 0.10 & 0.20 & 24.3 & 24.3 & 87.9 \\
\hline Urban sludge (US) & 38.1 & 26.4 & 2.50 & 1.77 & 7.4 & 7.4 & 55.7 \\
\hline Bovine manure $(\mathrm{BM})$ & 78.0 & 33.9 & 1.22 & 1.20 & 6.2 & 6.2 & 31.4 \\
\hline \multicolumn{8}{|c|}{ Field experiment } \\
\hline Hydrolytic lignin (HL) & 58.6 & 47.4 & 0.47 & 0.16 & 0.9 & 0.9 & 5.1 \\
\hline Hydrolytic slime (HS) & 59.4 & 46.8 & 1.52 & 0.49 & 14.2 & 14.2 & 33.7 \\
\hline Defecation mud (DM) & 28.5 & 4.0 & 0.25 & 0.18 & 20.9 & 20.9 & 87.5 \\
\hline Urban sludge (US) & 32.5 & 25.0 & 2.51 & 1.73 & 7.6 & 7.6 & 64.7 \\
\hline Bovine manure (BM) & 40.5 & 17.1 & 1.06 & 0.63 & 5.6 & 5.6 & 59.6 \\
\hline
\end{tabular}

*The abbreviations on the right will further stand for the given residue. 
The hydrolytic residues and the obtained compositions were incorporated in a dosage of $60 \mathrm{~g}$ of wet mass per $1 \mathrm{~kg}$ of soil. The field experiment was carried out on a plot from the mentioned farm. The compositions from residues were incorporated in a dosage of $100 \mathrm{t} / \mathrm{ha}$. The total quantity of calcium in 50 tons of sludge is equal to the quantity of changeable sodium in the $0-60 \mathrm{~cm}$ layer attested in the most alkaline parts of the experimental field. Each variant was repeated four times. The surface of the plots was $8 \times 20 \mathrm{~m}$. The materials were applied only once during the autumn ploughing at the depth of 18-22 cm. Bovine manure + gypsum was used in the experiment as comparison, a traditional procedure that is used at present for the amelioration of soils affected by salinity.

\section{Results and discussion}

Because of the contents of organic matter such as calcium, nitrogen, phosphorus and other fertilizing elements, and of possession of exceptional physical properties, the researched residues influenced considerably the on the fertility of the chernozem solonets.

The obtained results in the vegetation vessels experiment demonstrate that the apparent density was reduced by $0.08-0.12 \mathrm{~g} / \mathrm{cm} 3$ in the experimented variants (Table 2).

The impact of hydrolytic residues and their compositions on the physical properties of chernozem solonets. Vegetation vessels experiment

\begin{tabular}{|c|c|c|c|c|c|c|c|c|}
\hline $\begin{array}{c}\text { Variant } \\
\text { (dosage in } \mathrm{g} / \mathrm{kg} \\
\text { soil) }\end{array}$ & $\begin{array}{c}\text { Appa- } \\
\text { rent } \\
\text { density } \\
\text { g/cm }\end{array}$ & $\begin{array}{c}\text { Total } \\
\text { porosi-ty } \\
\%\end{array}$ & $\begin{array}{c}\text { Air } \\
\text { porosi-ty } \\
\text { for field } \\
\text { capaci-ty, } \\
\%\end{array}$ & $\begin{array}{l}\text { Saturated } \\
\text { soil per- } \\
\text { meabili-ty } \\
\text { for water } \\
\mathrm{mm} / \mathrm{ha}\end{array}$ & $\begin{array}{c}\text { Field } \\
\text { capaci-ty } \\
\text { for water, } \\
\%\end{array}$ & $\begin{array}{l}\text { Parch- } \\
\text { ing } \\
\text { coeffi- } \\
\text { cient, } \%\end{array}$ & $\begin{array}{l}\text { Use-ful } \\
\text { water } \\
\text { capa- } \\
\text { city, \% }\end{array}$ & $\begin{array}{l}\text { Penetra- } \\
\text { tion } \\
\text { resistan- } \\
\text { ce, } \mathrm{kg} / \mathrm{cm}^{2}\end{array}$ \\
\hline \multicolumn{9}{|c|}{1987 , the $6^{\text {th }}$ year of application } \\
\hline $\begin{array}{l}\text { Control without } \\
\text { residues }\end{array}$ & 1.31 & 50 & 14 & 0.6 & 27.3 & 16.1 & 11.2 & 11.6 \\
\hline $\mathrm{HL}, 60$ & 1.19 & 54 & 15 & 4.0 & 35.0 & 13.8 & 21.2 & 6.5 \\
\hline $\mathrm{HS}, 60$ & 1.21 & 53 & 14 & 2.4 & 32.0 & 14.0 & 18.0 & 8.5 \\
\hline HS, $15+U S, 45$ & 1.23 & 52 & 15 & 3.0 & 30.4 & 14.9 & 15.5 & 8.9 \\
\hline HS, $15+U S, 45$ & 1.20 & 55 & 20 & 2.9 & 29.4 & 13.8 & 15.6 & 7.1 \\
\hline $\mathrm{HL}, 45+\mathrm{DM}, 15$ & 1.21 & 53 & 11 & 3.7 & 34.5 & 14.1 & 20.4 & 6.9 \\
\hline LD 5\% & 0,066 & 2.1 & 2.3 & 0.56 & 2.73 & 1.25 & - & 0.58 \\
\hline
\end{tabular}

The soil resistance to penetration decreased by 1.3-1.8 times. A tendency of increasing the total porosity was observed. The soil permeability increased by 4-7 times in comparison with the control soil. The residues contributed to the decrease of the parching coefficient by 2.0-2.3\% and to the increase of water capacity by 2.7-7.2\%. Simultaneously the range of soil capacity for useful water increased from $11.2 \%$ for the control plot, which is characterized as average, to $15.2-21.2 \%$ for the amended variants which is evaluated as high and very high for the agricultural fields [1].

It is known the fact that the improvement of physical properties is due, first of all, to the reduction of sodium contents and the enrichment of the absorptive complex with calcium. Even in the first year of application the hydrolytic residues and their compositions increased the contents of changeable calcium from 8.8 to 12.7-14.1 me/100 g of soil (Table 3).

Table 3

Impact of hydrolytic residues and their compositions on the changeable cations in the chernozem solonets. Vegetation experiment

\begin{tabular}{|c|c|c|c|c|c|c|}
\hline \multirow[t]{2}{*}{$\begin{array}{c}\text { Variant } \\
\text { (dosage in } \mathrm{g} / \mathrm{kg} \text { soil) }\end{array}$} & \multicolumn{4}{|c|}{$\begin{array}{c}\text { me/100g } \\
\% \text { of the sum }\end{array}$} & \multicolumn{2}{|c|}{$\%$ of the total } \\
\hline & $\mathrm{Ca}++$ & $\mathrm{Mg}++$ & $\mathrm{Na}+$ & total & $\mathrm{Ca}++$ & $\mathrm{Na}+$ \\
\hline \multicolumn{7}{|c|}{ 1982, first year of application } \\
\hline Control & 8.8 & 9.1 & 4.6 & 22.5 & 39 & 21 \\
\hline HL,60 & 13.2 & 8.0 & 2.9 & 24.1 & 55 & 12 \\
\hline $\mathrm{HS}, 60$ & 13.3 & 8.0 & 2.5 & 23.8 & 56 & 10 \\
\hline HS, $15+\mathrm{US}, 30+\mathrm{DM}, 15$ & 14.1 & 7.4 & 1.9 & 23.4 & 60 & 8 \\
\hline HS, $15+\mathrm{US}, 45$ & 13.4 & 6.6 & 1.5 & 21.5 & 62 & 7 \\
\hline HL,30+DM,30 & 12.7 & 6.1 & 1.2 & 20.9 & 64 & 6 \\
\hline $\mathrm{LD}, 5 \%$ & 1.6 & 0.9 & 0.2 & 4.3 & 6 & 2 \\
\hline
\end{tabular}


Continuation of the table 3

\begin{tabular}{|l|c|c|c|c|c|c|}
\hline \multicolumn{9}{|c|}{1987, the $6^{\text {th }}$ year of application } \\
\hline Control & 9.5 & 9.1 & 3.0 & 21.6 & 44 & 14 \\
\hline HL,60 & 13.7 & 10.1 & 1.4 & 25.2 & 54 & 6 \\
\hline HS,60 & 14.6 & 8.9 & 1.1 & 24.6 & 59 & 5 \\
\hline HS,15+US,30+DM,15 & 17.1 & 7.2 & 0.2 & 24.5 & 70 & 1 \\
\hline HS,15+US,45 & 15.9 & 8.0 & 1.1 & 25.0 & 64 & 4 \\
\hline HL,30+DM,30 & 16.2 & 7.8 & 0.9 & 24.9 & 71 & 4 \\
\hline LD, 5\% & 1.6 & 0.9 & 0.1 & 2.7 & 6 & 0.4 \\
\hline
\end{tabular}

The concentration of sodium in the absorptive complex was reduced by 1.7-3.8 me/100 g. The sodium was substituted more intensively and more completely in the soil treated with comparative mixtures and the application of separate hydrolytic residues. In the sixth year of application, the sodium had $1 \%$ of the changeable capacity in the variant treated with a mixture of, for example, $15 \mathrm{~g} / \mathrm{kg}$ of hydrolytic lignin $+30 \mathrm{~g}$ of urban sludge $+15 \mathrm{~g}$ of defecation mud. In the field experiment the impact of the compositions from residues was analogous to that from the vegetation vessels. Since the first year of application, a significant increase of calcium and a reduction of sodium in the absorptive complex have been observed in all the experimental variants (Table 4).

Table 4

Modifications in the contents of changeable cations in the chernozem solonets at the application of various hydrolytic residue compositions. Field experiment

\begin{tabular}{|c|c|c|c|c|c|c|c|}
\hline \multirow{2}{*}{$\begin{array}{c}\text { Variant } \\
\text { (residue dosage, } t / h a)\end{array}$} & \multirow{2}{*}{$\begin{array}{c}\text { Depth, } \\
\text { cm }\end{array}$} & \multicolumn{4}{|c|}{$\mathrm{me} / 100 \mathrm{~g}$} & \multicolumn{2}{|c|}{$\%$ of the total } \\
\hline & & $\mathrm{Ca}++$ & Mg++ & $\mathbf{N a}+$ & Total & $\mathbf{C a}++$ & $\mathbf{N a}+$ \\
\hline \multicolumn{8}{|c|}{$5^{\text {th }}$ year of application } \\
\hline \multirow{3}{*}{ Control without residues } & $0-20$ & 8.3 & 9.8 & 4.7 & 22.8 & 36 & 21 \\
\hline & $20-40$ & 7.2 & 10.7 & 6.1 & 24.0 & 30 & 25 \\
\hline & $40-60$ & 5.8 & 10.9 & 6.5 & 23.2 & 25 & 28 \\
\hline Average content & $0-60$ & 7.1 & 10.5 & 5.8 & 23.3 & 30 & 25 \\
\hline \multirow{3}{*}{ BM, 100+ gypsum,10 } & $0-20$ & 14.1 & 9.0 & 1.2 & 24.3 & 58 & 5 \\
\hline & $20-40$ & 10.3 & 10.0 & 2.8 & 23.1 & 45 & 12 \\
\hline & $40-60$ & 6.1 & 13.4 & 5.3 & 24.8 & 25 & 21 \\
\hline Average content & $0-60$ & 10.2 & 10.8 & 3.1 & 24.1 & 43 & 13 \\
\hline \multirow{3}{*}{ HL, $50+\mathrm{HS}, 50$} & $0-20$ & 11.2 & 9.3 & 2.8 & 23.3 & 48 & 12 \\
\hline & $20-40$ & 8.3 & 10.2 & 3.6 & 22.4 & 37 & 16 \\
\hline & $40-60$ & 5.5 & 12.7 & 6.1 & 24.3 & 23 & 25 \\
\hline Average content & $0-60$ & 8.3 & 10.7 & 4.2 & 23.3 & 36 & 18 \\
\hline \multirow{3}{*}{ HL,50+HS 50+, gypsum 10} & $0-20$ & 14.5 & 8.9 & 1.1 & 24.5 & 59 & 5 \\
\hline & $20-40$ & 10.2 & 11.6 & 2.5 & 24.3 & 42 & 10 \\
\hline & $40-60$ & 6.9 & 13.1 & 5.1 & 25.1 & 28 & 20 \\
\hline Average content & $0-60$ & 10.5 & 11.2 & 2.9 & 24.6 & 43 & 12 \\
\hline \multirow{3}{*}{ HL, 25+HS,25+US, 50} & $0-20$ & 13.2 & 7.2 & 0.8 & 21.2 & 62 & 4 \\
\hline & $20-40$ & 11.7 & 6.7 & 1.4 & 19.8 & 59 & 7 \\
\hline & $40-60$ & 12.6 & 8.8 & 2.1 & 23.5 & 54 & 9 \\
\hline Average content & $0-60$ & 12.5 & 7.6 & 1.4 & 21.5 & 58 & 6 \\
\hline \multirow{3}{*}{ HL,25+HS,25+DM,50 } & $0-20$ & 17.2 & 7.8 & 0.7 & 25.7 & 67 & 3 \\
\hline & $20-40$ & 12.6 & 7.7 & 1.8 & 22.1 & 57 & 8 \\
\hline & $40-60$ & 9.0 & 10.9 & 3.6 & 23.5 & 38 & 15 \\
\hline Average content & $0-60$ & 12.9 & 8.8 & 2.0 & 23.8 & 54 & 9 \\
\hline \multirow{3}{*}{$\begin{array}{c}\mathrm{HL}, 10+\mathrm{HS}, 10+\mathrm{US}, 30+ \\
+\mathrm{DM}, 50\end{array}$} & $0-20$ & 16.9 & 7.6 & 0.7 & 25.2 & 67 & 3 \\
\hline & $20-40$ & 12.3 & 8.8 & 1.7 & 22.8 & 54 & 7 \\
\hline & $40-60$ & 9.4 & 10.2 & 3.5 & 23.1 & 41 & 15 \\
\hline Average content & $0-60$ & 12.9 & 8.9 & 2.0 & 23.7 & 54 & \\
\hline
\end{tabular}

Though the residue mixtures were incorporated in the $0-20 \mathrm{~cm}$ layer, the substitution of sodium in the absorptive complex by calcium spread to the lower layers as well. The mixtures that contained in their composition urban sludge 
or defecation mud manifested themselves by a more pronounced amelioration effect. The mixtures containing bovine manure + gypsum and hydrolytic lignin, 50 + hydrolytic slime, 50+ gypsum, 10 t/ha had the same useful effect on the absorptive complex. A less pronounced ameliorative effect was observed in the variant treated with hydrolytic lignin, $50 \mathrm{t}+$ hydrolytic slime, $50 \mathrm{t} / \mathrm{ha}$.

We suppose that the ameliorative impact on the deep layers is done by the soluble compounds or the ones found in suspension and transferred with water from the administrated residues.

In the first year of residues application, a part of the substituted sodium from the absorptive complex remained in the soil solution. In the vegetation vessels experiment the concentration of soluble sodium on the control variant was of $3.46 \mathrm{me} / 100 \mathrm{~g}$ of soil, while on the treated variants it significantly exceeded this value (Table 5).

Table 5

Impact of hydrolytic residues and their compositions on the contents of soluble salts in the chernozem solonets me/100 $\mathrm{g}$ of soil. Vegetation vessels experiment

\begin{tabular}{|c|c|c|c|c|c|c|c|c|}
\hline Variant & $\mathrm{NCO}_{3}$ & $\mathrm{Cl}$ & SO4 & $\mathbf{C A}++$ & Mg++ & $\mathbf{N a}+$ & $\mathbf{K}+$ & $\begin{array}{c}\text { Total } \\
\text { residue, } \\
\%\end{array}$ \\
\hline \multicolumn{9}{|c|}{1982 , the $1^{\text {st }}$ year of application } \\
\hline Control & 1.08 & 0.12 & 3.28 & 0.32 & 0.34 & 3.46 & 0.02 & 0.30 \\
\hline HL,60 & 0.52 & 0.16 & 4.14 & 0.56 & 0.52 & 3.70 & 0.04 & 0.34 \\
\hline HS,60 & 0.76 & 0.20 & 4.83 & 1.16 & 0.76 & 3.81 & 0.06 & 0.41 \\
\hline HS,15+US,30+DM,15 & 0.92 & 0.20 & 4.85 & 1.00 & 0.88 & 4.02 & 0.07 & 0.42 \\
\hline HS, $15+\mathrm{US}, 45$ & 1.20 & 0.18 & 3.43 & 0.56 & 0.46 & 3.75 & 0.04 & 0.31 \\
\hline HL,30+DM,30 & 1.16 & 0.08 & 3.28 & 0.60 & 0.40 & 3.48 & 0.04 & 0.33 \\
\hline $\mathrm{LD}, 5 \%$ & 0.17 & 0.04 & 1.02 & 0.28 & 0.18 & 0.69 & 0.01 & 0.09 \\
\hline \multicolumn{9}{|c|}{1987, the $6^{\text {th }}$ year of application } \\
\hline Control & 1.04 & 0.04 & 2.43 & 0.36 & 0.16 & 2.96 & 0.03 & 0.26 \\
\hline HL,60 & 0.50 & 0.20 & 0.47 & 0.40 & 0.10 & 0.65 & 0.02 & 0.08 \\
\hline $\mathrm{HS}, 60$ & 0.30 & 0.10 & 0.70 & 0.50 & 0.20 & 0.37 & 0.03 & 0.08 \\
\hline HS,15+US,30+DM,15 & 0.60 & 0.10 & 0.62 & 0.50 & 0.30 & 0.51 & 0.01 & 0.09 \\
\hline HS, $15+U S, 45$ & 0.60 & 0.30 & 0.11 & 0.20 & 0.20 & 0.57 & 0.04 & 0.07 \\
\hline HL,30+DM,30 & 0.80 & 0.20 & 0.15 & 0.30 & 0.30 & 0.54 & 0.01 & 0.08 \\
\hline $\mathrm{LD}, 5 \%$ & 0.05 & 0.02 & 0.06 & 0.05 & 0.03 & 0.08 & 0.004 & 0.02 \\
\hline
\end{tabular}

In enrichment of the liquid phase with salts is also due to the incorporated residues. In all the experimented variants the concentration of $\mathrm{Ca}++$ and $\mathrm{SO} 4$ - ions increased. Probably, this fact is due to the contents and the mobility of these elements in the corresponding residues. Simultaneously, the increase of soluble ions concentration in the first year of application conditioned the increase of total residue in all the experimented variants compared to the control variant. The amelioration of the solonets is considered complete when the salts are removed from the profile. In the following years the hydro-physical properties of the solonets improved. More precipitations fell and gradually the salts were washed, thus desalinizing the soil. In the sixth year, the total residue in the experimental variants was reduced by 2.9 -3.7 times compared to the control one. Among the experimented compositions in the field experiment, the hydrolytic lignin, $10 \mathrm{t}+$ hydrolytic slime, $10 \mathrm{t}+$ urban sludge, $30 \mathrm{t}+$ defecation mud, $50 \mathrm{t} / \mathrm{ha}$ and hydrolytic lignin, $25 \mathrm{t}$ + hydrolytic slime, $25 \mathrm{t}+$ urban sludge, $50 \mathrm{t} /$ ha had a more advantageous impact on the desalinization.

In the treated variants the reaction of the solonets improved. The average values of $\mathrm{pH}$ for the three years in the 0-20 cm layer were of 0.4-0.6 units smaller than on the control variant (Table 6).

By increasing the hydrogen ions activity, the organic residues increase simultaneously the tamponing capacity of the solonets [2]. In the ploughed layer, where the compositions of hydrolytic residues, which contained defecation mud, were incorporated a moderate increase $(0.6-1.0 \%)$ of the calcium carbon was observed. There exists the hypothesis that a moderate content of $\mathrm{CaCo} 3$ positively influences the structure and the tamponing capacity and maintains the soil reaction in the limits of the average values [3].

By increasing the hydrogen ions activity, the organic residues increase simultaneously the tamponing capacity of the solonets [2]. In the ploughed layer, where the compositions of hydrolytic residues, which contained defecation mud, were incorporated a moderate increase $(0.6-1.0 \%)$ of the calcium carbon was observed. There exists the hypothesis that a moderate content of $\mathrm{CaCo} 3$ positively influences the structure and the tamponing capacity and maintains the soil reaction in the limits of the average values [3]. 